\title{
Introduction to time series analysis *
}

\author{
Jean-Marie Dufour $^{\dagger}$ \\ First version: December 1998 \\ Revised: January 2003 \\ This version: January 8, 2008 \\ Compiled: January 8, 2008, 6:12pm
}

* This work was supported by the William Dow Chair in Political Economy (McGill University), the Canada Research Chair Program (Chair in Econometrics, Université de Montréal), the Bank of Canada (Research Fellowship), a Guggenheim Fellowship, a Konrad-Adenauer Fellowship (Alexander-von-Humboldt Foundation, Germany), the Institut de finance mathématique de Montréal (IFM2), the Canadian Network of Centres of Excellence [program on Mathematics of Information Technology and Complex Systems (MITACS)], the Natural Sciences and Engineering Research Council of Canada, the Social Sciences and Humanities Research Council of Canada, the Fonds de recherche sur la société et la culture (Québec), and the Fonds de recherche sur la nature et les technologies (Québec), and a Killam Fellowship (Canada Council for the Arts).

$\dagger$ William Dow Professor of Economics, McGill University, Centre interuniversitaire de recherche en analyse des organisations (CIRANO), and Centre interuniversitaire de recherche en économie quantitative (CIREQ). Mailing address: Department of Economics, McGill University, Leacock Building, Room 519, 855 Sherbrooke Street West, Montréal, Québec H3A 2T7, Canada. TEL: (1) 514398 8879; FAX: (1) 514 398 4938; e-mail: jean-marie.dufour@mcgill.ca. Web page: http://www.jeanmariedufour.com 


\section{Contents}

1. Notion of time series $\quad 1$

2. Examples of time series $\quad 2$

3. Objectives and problems of time series analysis 9

3.1. General objectives . . . . . . . . . . . . . . . . . . . . . . . 9

3.2. Important problems in time series analysis . . . . . . . . . . . . . 9

4. Types of models $\quad 10$

4.1. Deterministic models . . . . . . . . . . . . . . . . . . . . 10

4.2. Stochastic models . . . . . . . . . . . . . . . . . . . . . 11

4.3. Important types of deterministic trends . . . . . . . . . . . . . . . 11

4.4. Important categories of stochastic models . . . . . . . . . . . . . . . . . 12

4.4.1. Adjustment models . . . . . . . . . . . . . . . . . . . . 12

4.4.1.1. Important types of adjustment models . . . . . . . . . 12

4.4.1.2. Trend estimation and elimination . . . . . . . . . . . 12

4.4.1.3. Persons decomposition . . . . . . . . . . . . . 12

4.4.2. Filtering models (generalized moving averages) . . . . . . . . 13

4.4.3. Autopredictive models . . . . . . . . . . . . . . . 13

4.4.4. Explanatory models . . . . . . . . . . . . . 13 


\section{Notion of time series}

Most statistical methods are aimed to be applied to independent experiments or sample survey results: observation ordering has no special meaning (as occurs typically, e.g., in biology, agronomy, sociology, etc.).

In economics, data often take the form of sequences (series) of observations on one or several variables taken at different dates: these observations cannot typically be assumed to be independent.

1.1 Definition (Time series). We call a time series any (finite or finite) sequence observations $\left(X_{t}: t \in T\right)$ indexed by an ordered set ("time").

\subsection{Important types of time series}

1. Continuous series _ In certain fields (e.g., physics), some variables $X_{t}$ can be observed continuously, i.e. the time index $t$ can take all the values in an interval of real numbers.

In such a case, we speak of a continuous series. Such series are however quite rare in economic data.

2. Discrete series_A series is discrete when the set of the possible values $t$ is a discrete set, i.e. $T$ can be viewed as a subset of the integers.

There are two important types of discrete series, depending on whether the observations represent

(a) levels: series registered instantaneously (e.g., prices, stocks), or

(b) flows : cumulated series over a time interval (e.g., income, income, consumption).

When analyzing a flow series, it is important to be aware of the time interval involved. 


\section{Examples of time series}

1. Real gross national product in the United States, 1872-1985 (annual). Source: Barro (1987, Figure 1.1).

Secular trend apparent.

2. Rate of growth of real gross national product in the United States, 1873-1985 (annual).

Source: Barro (1987, Figure 1.2).

No trend.

3. Unemployment rate in the United States, 1873-1985 (annual).

Source: Barro (1987, Figure 1.3).

No trend. Series less volatile since 1945.

4. Price level in the United States, 1870-1985 (annual).

Source: Barro (1987, Figure 1.4).

Strong trend. Possibility of a structural change.

5. Inflation rate in the United States, 1870-1985 (annual).

Source: Barro (1987, Figure 1.5).

No trend. Possibility of a structural change around 1950.

6. Logarithm of retail sales of men's and boys' clothing in the United States, 1967-1979 (quarterly).

Source: Hillmer, Bell, and Tiao (1983, Figure 3.12, page 87).

Trend plus seasonal fluctuations. 


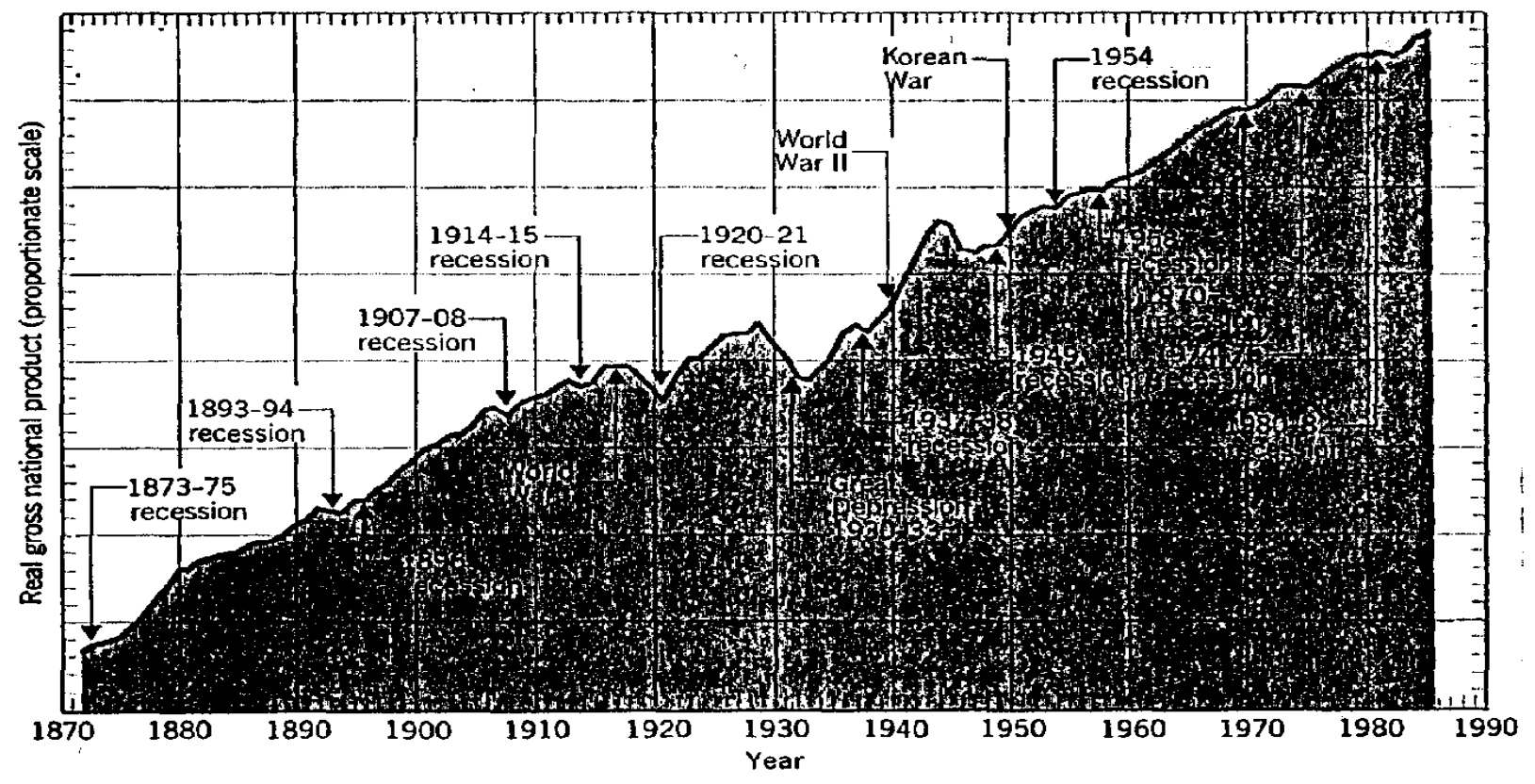

Figure 1.1 The Behavlor of Output in the United States, 1872-1985

Sources for Figures 1.1-1.5:

For real GNP-Recent values are from the U.S. Commerce Department, U.S. Survey of Current Business. Figures back to 1918 are from the U.S. Commerce Department, National Income and Product Accounts of the U.S., 1929-76. For 1872-1917, the values are from Christina Romer, "The Prewar Business Cycle Reconsidered: New Estimates of Gross National Product, 1872-1918," Princeton University, May 1985, Table 1.

For the GNP deflator-Sources as above since 1918. For 1909-17, figures are from the U.S. Commerce Department, National Incorre and Product Accounts of the U.S., 1929-76. For 1889-1908, the numbers are based on John Kendrick, Productivity Trends in the United States, Princeton University Press, Princeton, N.J., 1961, Tables A-1 and A-III. For 1869-88, the data are unpublished estimates of Robert Gallman.

For the unemployment rate-The figures are the number unemployed divided by the cotal labor force, which includes military personnel. Data since 1930 are from Economic Report of the President, 1985, Table B-29; 1983, Table B-29; 1970, Table C22. The data from 1933-43 are adjusted to classify federal emergency workers as employed, as discussed in Michael Darby, "Three-and-a-Half Million U.S. Employees Have been Mislaid: Or, an Explanation of Unemployment, 1934-1941," Journal of Political Economy, February 1976. Values for 1890-1929 are based on Christina Romer, "Spurious Volatility in Historical Unemployment Data," Journal of Political Economy, February 1986, Table 9.

Figure 1. Real gross national product in the United States, 1872-1985 (annual) Source: Barro (1987, Chapter 1) 


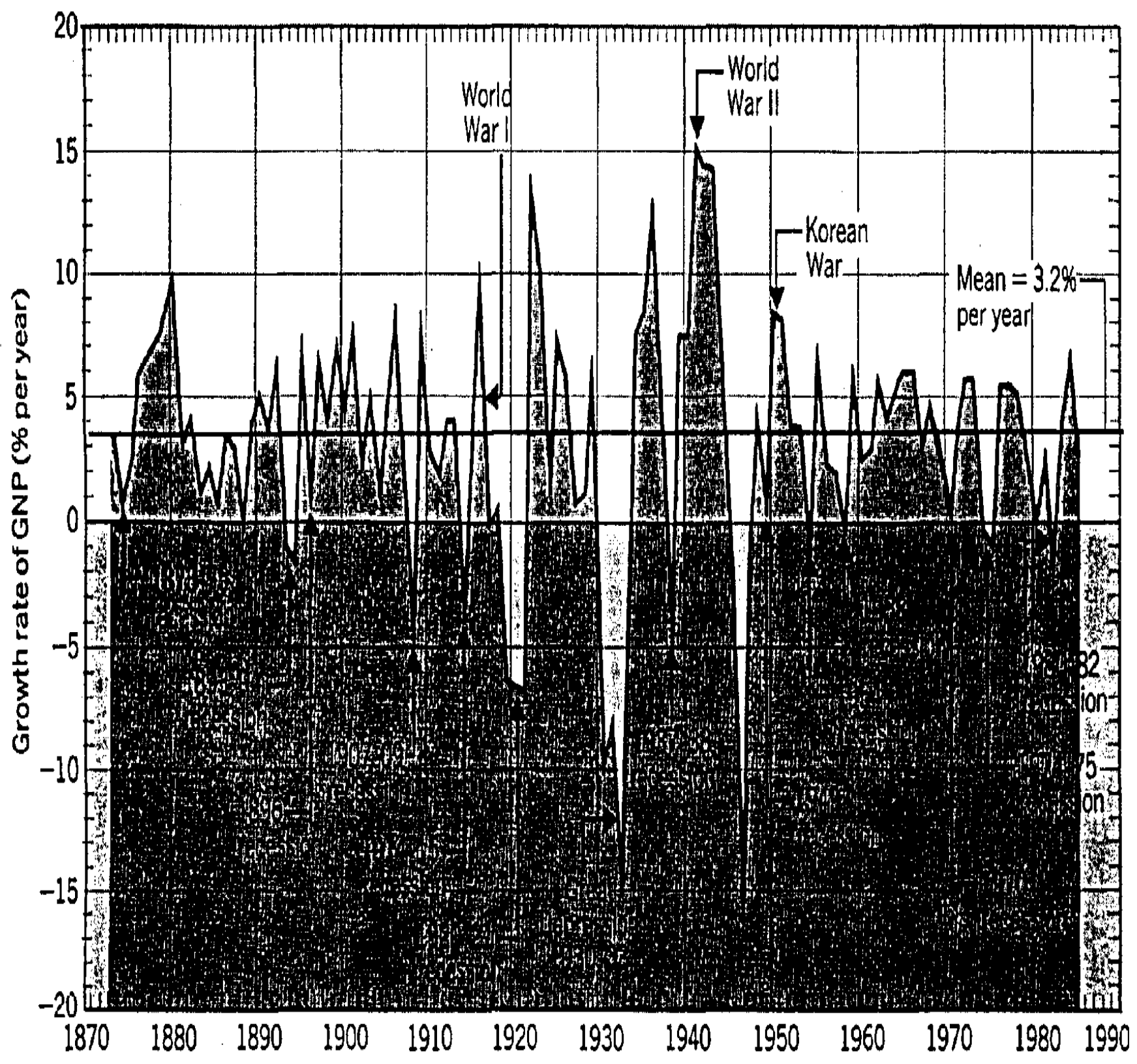

Figure 2. Rate of growth of real gross national product in the United States, 1873-1985 (annual)

Source: Barro (1987, Chapter 1) 


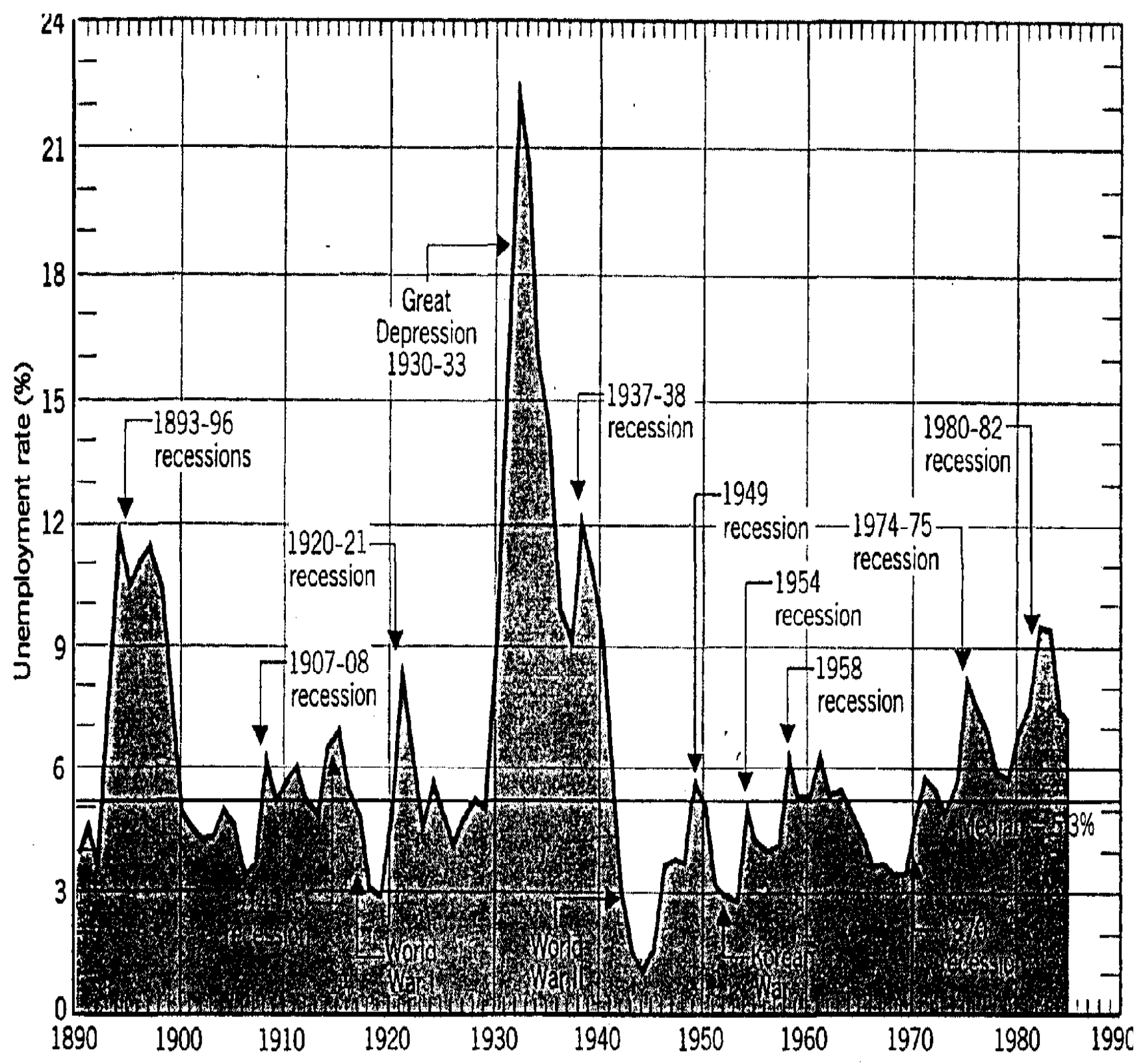

Figure 3. Unemployment rate in the United States, 1873-1985 (annual) Source: Barro (1987, Chapter 1) 


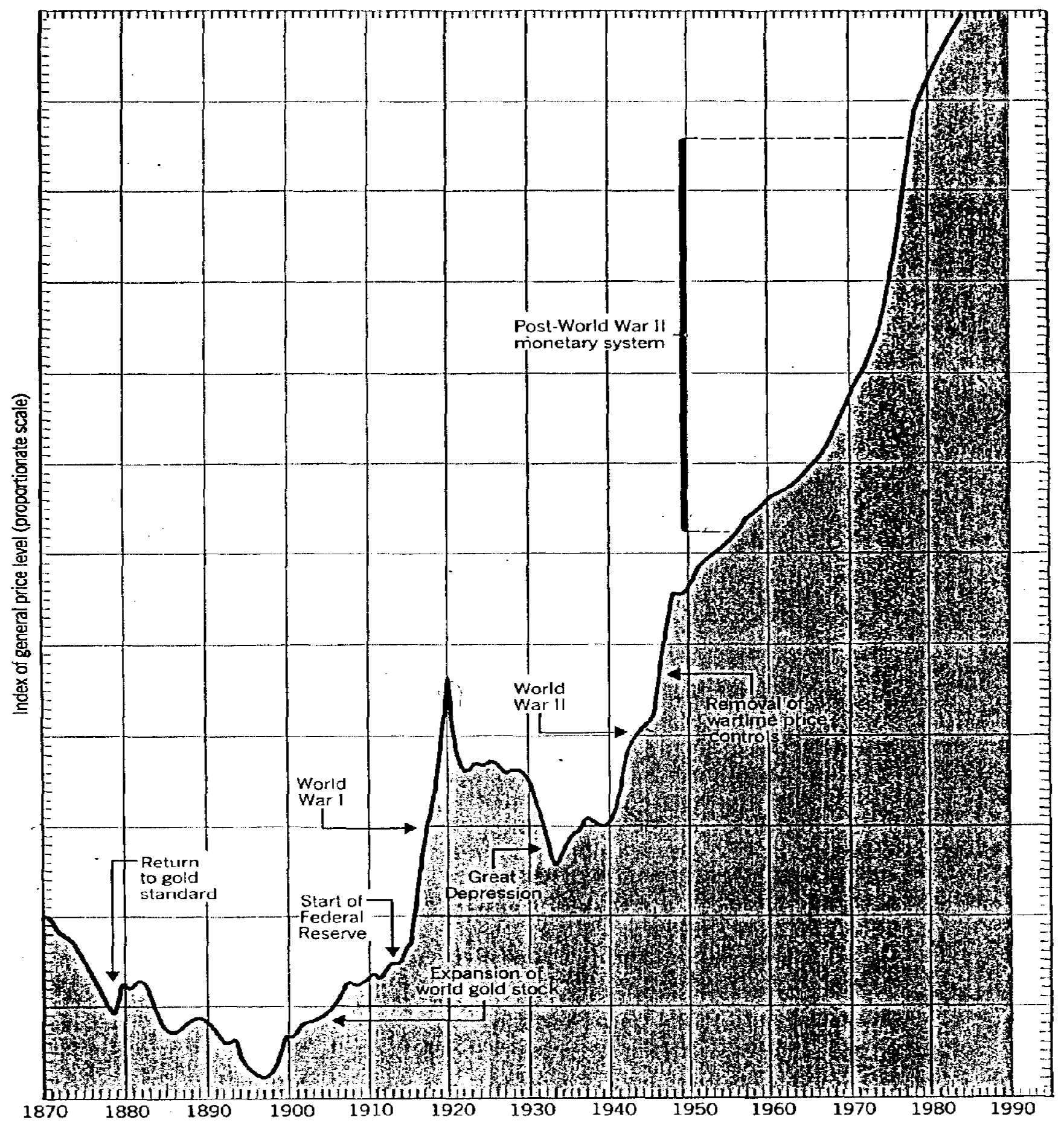

Figure 4. Price level in the United States, 1870-1985 (annual) Source: Barro (1987, Chapter 1) 


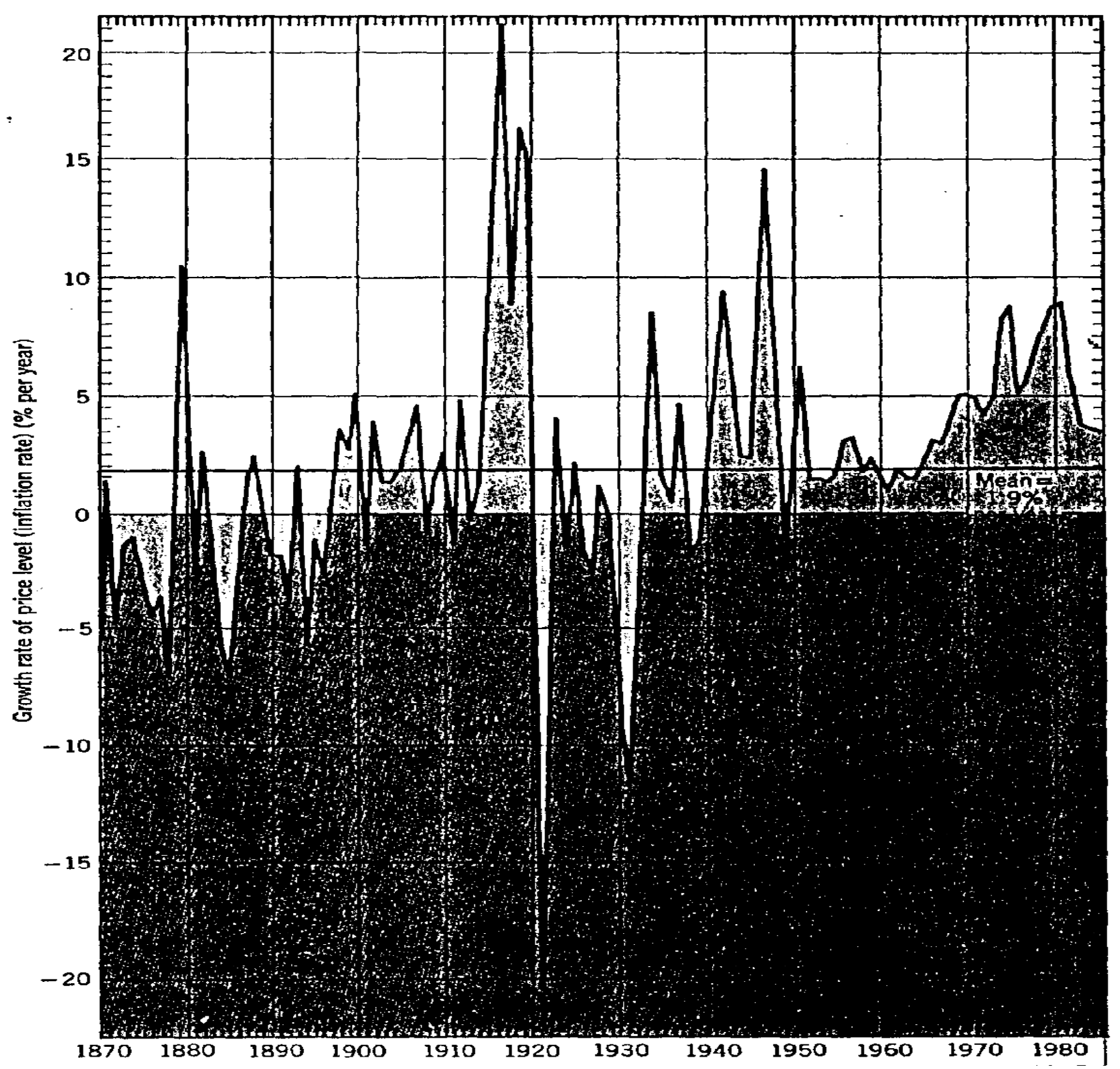

Figure 5. Inflation rate in the United States, 1870-1985 (annual)

Source: Barro (1987, Chapter 1) 


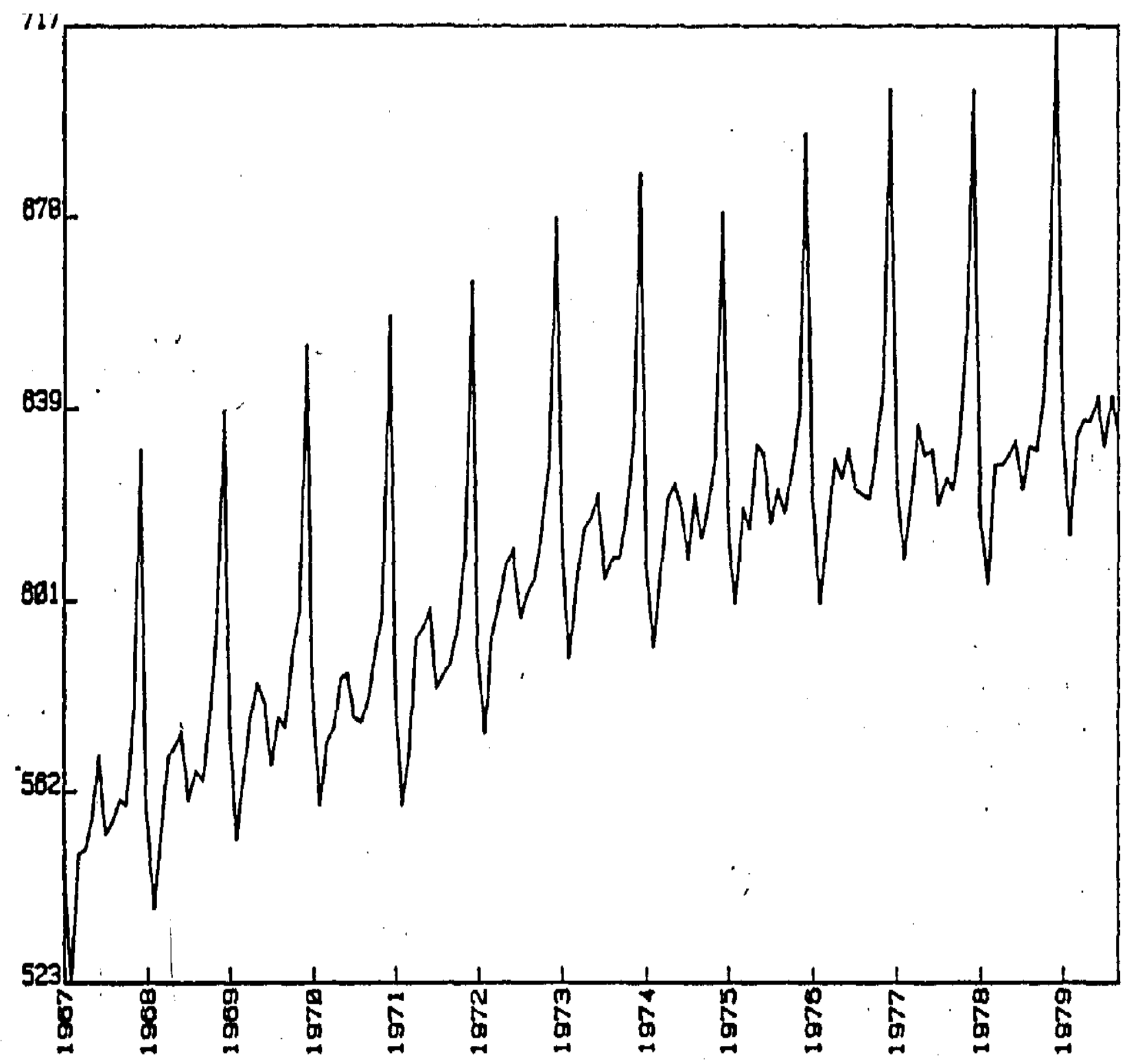

Figure 6. Logarithm of retail sales of men's and boys' clothing in the United States, 1967-1979 (quarterly)

Source: Hillmer, Bell, and Tiao (1983) 


\section{Objectives and problems of time series analysis}

\subsection{General objectives}

1. To develop models for describing the behavior of individual or multiple time series.

2. To propose a methodology for

- specifying

- estimating

- validating (assessing)

an appropriate model for specific data.

\subsection{Important problems in time series analysis}

\subsubsection{Prediction}

Given $X_{1}, \ldots, X_{T}$, we wish to estimate an observed value $X_{T+h}$.

Prediction can be pointwise, $\hat{X}_{T}(h)$, or take the form of an interval (predictive interval): $\left[\hat{X}_{T}^{1}(h), \hat{X}_{T}^{2}(h)\right]$

\subsubsection{Decomposition}

The most frequent decomposition problems are:

1. to estimate a trend;

2. to eliminate a trend (detrending);

3. to estimate seasonal fluctuations (seasonal components);

4. to eliminate seasonal fluctuations (seasonal adjustment).

For example, suppose a series $X_{t}$ can be represented in the form:

$$
X_{t}=Z_{t}+S_{t}+u_{t}
$$

where:

$Z_{t}$ is a trend (smooth function of time),

$S_{t}$ is a seasonal component,

$u_{t}$ is an irregular component (random perturbation).

The four decomposition problems mentioned above may then be interpreted as follows: 
1. estimate $Z_{t}$;

2. estimate $X_{t}-Z_{t}$;

3. estimate $S_{t}$;

4. estimate $X_{t}-S_{t}$.

3.2.3 Detection and modeling of breakpoints (structural change analysis).

3.2.4 Analysis of the dynamic links between:

1. causality;

2. lead-lag relationships.

3.2.5 Separation between short-run and long-run relations (e.g., through the concept of cointegration).

3.2.6 Analysis of expectations.

\subsubsection{Control.}

\section{Types of models}

\subsection{Deterministic models}

A deterministic model is a model not bases on probability theory.

There are two main types of deterministic models;

1. deterministic functions of time:

$$
X_{t}=f(t)
$$

2. recurrence equations:

$$
X_{t}=f\left(t, X_{t-1}, X_{t-2}, \ldots\right)
$$

Provided $f(\cdot)$ and (if required) past values of $X_{t}$ are known, a deterministic model for $X_{t}$ allows one to predict perfectly the future of $X_{t}$. 


\subsection{Stochastic models}

A stochastic model is a model where the variables $X_{t}$ in a series are viewed as random variables.

When we consider a series $\left(X_{t}: t \in T\right)$ of random variables, we say we have a stochastic process (or a random function). The theory of stochastic processes is the theoretical mathematical foundation for studying stochastic time series models.

\subsection{Important types of deterministic trends}

Different types of deterministic trends can be obtained by varying the functional form of $f(t)$. Especially important ones the following.

\section{Trigonometric trend:}

$$
f(t)=A_{0}+\sum_{j=1}^{q}\left[A_{j} \cos \left(\omega_{j} t\right)+B_{j} \sin \left(\omega_{j} t\right)\right] .
$$

This function is periodic (or quasi-periodic). From the very start of time series analysis, such models were considered in order to represent series whose behavior appeared to exhibit periodicities. An important issue in such analyses consists in determining the important frequencies $\omega_{j}$ (harmonic analysis or spectral analysis).

\section{Linear trend:}

$$
f(t)=\beta_{0}+\beta_{1} t
$$

\section{Polynomial trend:}

$$
f(t)=\beta_{0}+\beta_{1} t+\cdots+\beta_{k} t^{k} .
$$

4. Exponential curve:

$$
f(t)=\beta_{0}+\beta_{1} r^{t} .
$$

5. Logistic curve:

$$
f(t)=\frac{1}{\beta_{0}+\beta_{1} r^{t}}, \text { where } r>0 .
$$

6. Gompertz curve:

$$
f(t)=\exp \left\{\beta_{0}+\beta_{1} r^{t}\right\}, \text { where } r>0 .
$$




\subsection{Important categories of stochastic models}

\subsubsection{Adjustment models}

$$
X_{t}=f\left(t, u_{t}\right)
$$

where:

$$
\begin{aligned}
& t \text { represents time, } \\
& u_{t} \text { is a random disturbance. }
\end{aligned}
$$

Usually, it is assumed that the $u_{t}$ 's are mutually independent or uncorrelated.

\subsubsection{Important types of adjustment models.}

1. Additive trend:

$$
X_{t}=f(t)+u_{t}
$$

2. Multiplicative trend:

$$
X_{t}=f(t) u_{t}
$$

where $f(t)$ is independent of (or uncorrelated with) $u_{t}$. Usually, it is assumed that $f(t)$ is a deterministic (non random) function of time as considered above. In certain cases, $f(t)$ can be viewed as random (unobserved components models).

4.4.1.2. Trend estimation and elimination. Methods for estimating or eliminating trends belong to two basic types:

1. global adjustment methods, where all the observations play equivalent roles;

2. local adjustment methods, where nearby observations (in time) play more important roles:

(a) moving averages;

(b) exponential smoothing.

4.4.1.3. Persons decomposition. In economics, the following standard decomposition (called the Persons decomposition) has often been used:

$$
X_{t}=Z_{t}+C_{t}+S_{t}+u_{t}
$$


where

$Z_{t}$ is a secular (long-run) trend,

$C_{t}$ is a relatively smooth deviation from the secular trend

(business cycle),

$S_{t}$ is a seasonal component,

$u_{t}$ is a random perturbation (unpredictible).

\subsubsection{Filtering models (generalized moving averages)}

$$
X_{t}=f\left(\ldots, u_{t-1}, u_{t}, u_{t+1}, \ldots\right)
$$

where the $u_{t}$ 's are random disturbances (independent or mutually uncorrelated random variables).

Important case - Moving average of order $q$ :

$$
X_{t}=\bar{\mu}+u_{t}-\sum_{j=1}^{q} \theta_{j} u_{t-j}
$$

\subsubsection{Autopredictive models}

$$
X_{t}=f\left(X_{t-1}, X_{t-2}, \ldots, u_{t}\right)
$$

where the $u_{t}$ 's are random disturbances.

Important case - Autoregressive process of order $p$ :

$$
X_{t}=\bar{\mu}+\sum_{j=1}^{p} \varphi_{j} X_{t-j}+u_{t} .
$$

\subsubsection{Explanatory models}

$$
X_{t}=f\left(Z_{t}^{*}, u_{t}\right)
$$

where $Z_{t}^{*}$ contains various explanatory variables (exogenous variables) and (possibly) lagged values of $X_{t}$. 


\section{References}

Anderson, T. W. (1971): The Statistical Analysis of Time Series. John Wiley \& Sons, New York.

BARRO, R. J. (1987): Macroeconomics. John Wiley \& Sons, New York, second edn.

Box, G. E. P., And G. M. Jenkins (1976): Time Series Analysis: Forecasting and Control. Holden-Day, San Francisco, second edn.

Gouriéroux, C., And A. Monfort (1997): Time Series and Dynamic Models. Cambridge University Press, Cambridge, U.K.

Hillmer, S. C., W. R. Bell, and G. C. Tiao (1983): "Modeling Considerations Considerations in Seasonal Adjustment of Economic Time Series," in Zellner (1983), pp. 74-100, With comments (101-124).

Zellner, A. (ed.) (1983): Applied Time Series Analysis of Economics Data. Bureau of the Census, Washington, D.C. 